\title{
DIRECTRICES COMUNITARIAS PARA LA RESTTTUCIÓN DE BIENES CULTURALES ILÍCITAMENTE EXPORTADOS
}

\author{
Jesús de la Ascensión \\ Salas Álvarez \\ Arqueólogo
}

\section{Bibliografía}

Reglamento (CEE) $n^{\circ}$ 3.91/1992 del Consejo, de 9 de Diciembre de 1992, relativo a la Exportación de Bienes Culturales (DOCE $n^{\circ}$ L 395/1, de 31 de Diciembre).

Directiva 93/7 (CEE) del Consejo, de 15 de Marzo de 1993, relativa a la Restitución de Bienes Culturales que hayan salido de forma ilegal del Territorio de un Estado Miembro (DOCE $n^{\circ}$ L 74, de 27 de Marzo).

Ley 16/1985, de 25 de Junio, del Patrimonio Histórico Español (BOE $n^{\circ} 155$, de 29 de Junio).

Real Decreto 111/1986, de 10 de Enero, por el que se desarrolla parcialmente la Ley 16/1985, de 25 de Junio, del Patrimonio Histórico Español (BOE $n^{\circ}$ 24, de 28 de Enero).

Real Decreto 64/1994, de 21 de Enero, por el que se modifica el Real Decreto 111/1986, de 10 de Enero, de desarrollo parcial de la Ley 16/1985, de 25 de Junio, del Patrimonio Histórico Español (BOE $n^{\circ} 52$, de 2 de Marzo).

Ley de Enjuiciamiento Civil, artículos 1.651 a 1.662.
La Directiva 93/7 CEE del Consejo de las Comunidades, de 15 de Marzo de 1993, relativa a la Restitución de Bienes Culturales que hayan salido de forma ilegal del territorio de un Estado Miembro (D.O.C.E. n. ${ }^{\circ}$ L74, de 27 de Marzo) supone un nuevo instrumento con el que cuentan las Administraciones para recuperar aquellos bienes culturales “...que hayan salido de forma ilegal del territorio de un Estado Miembro... infringiendo su legislación en materia de protección nacional o infringiendo..." lo dispuesto en el Reglamento (CEE) n. ${ }^{\circ}$ 3.9 I I/1992 del Consejo, de 9 de Diciembre, relativo a la Exportación de Bienes Culturales, y que entró en vigor el pasado I de Enero de 1993.

Esa legislación a que hace referencia la anterior Directiva Comunitaria es nuestra Ley 16/1985, de 25 de junio, del Patrimonio Histórico Español (BOE n. ${ }^{\circ}$ 155, de 29 de junio), que considera a la exportación ilegal como aquella que se realiza “...sin la expresa y previa autorización de la Administración del Estado...”, así como “...de los bienes declarados de interés cultural..." y “...la de aquellos otros, que, por su pertenencia al Patrimonio Histórico Español, la Administración del Estado declare expresamente inexportables...".

Su realización implica, a modo de sanción, que los bienes exportados “...pertenecen al Estado", como indica el Art. 29.I LPHE, que limita exclusivamente esa consecuencia a los bienes muebles que sean exportados “...sin la autorización requerida por el artículo 5 de esta Ley...”, olvidando la existencia de posibles exportaciones ilegales de BIC en las que no medie ningún tipo de autorización.

En la anterior Ley, se faculta a la Administración Española para "....realizar los actos conducentes a la total recuperación de los bienes ilegalmente exportados..." (Art. 29.2 LPHE), entendiéndose que con ello nos referimos a cualquiera de las modalidades de exportación ilegal, tanto a la realizada sin autorización como a la que versa sobre bienes inexplotables, ya que los bienes ilegalmente exportados son "...inalienables e inexplotables" (Art. 29.I (LPHE).

Así, para realizar todos los actos conducentes a la total recuperación de los bienes ilegalmente exportados, la Administración Española cuenta con esta Directiva Comunitaria, la cual entró “....en vigor... en los nueve meses siguientes a su adopción...” (Art.
I 8 Directiva 93/7), y cuya adopción, según su Exposición de Motivos, se debe a varios hechos:

a) La aparición de un mercado único y sin fronteras interiores

b) La necesidad de adoptar medidas garantizadoras de la protección de los bienes culturales en este espacio sin fronteras interiores.

c) La posibilidad de restablecer bienes culturales clasificados dentro del patrimonio nacional de cada Estado Miembro y que hayan salido de su territorio de una forma ilícita.

d) Limitar el ámbito de aplicación el presente sistema a objetos que pertenezcan a unas categorías comunes de bienes culturales, a los que habría que sumar aquellos bienes que forman parte de colecciones públicas o de inventarios de instituciones eclesiásticas.

e) La necesidad de establecer una colaboración administrativa entre los Estados Miembros por lo que a su Patrimonio Nacional se refiere, en estrecha relación con la cooperación de los mismos en materia de robos de obras de arte.

Partiendo de esta base, el Art. 2 de la Directiva 93/7 mantiene que "los bienes culturales que hayan salido de forma ilegal del territorio de un Estado miembro serán restituidos con arreglo al procedimiento $y$ en las condiciones previstas a la Presente Directiva", con lo cual esta disposición pasa a convertirse en el instrumento único para la recuperación de bienes culturales, colocándose por encima incluso de las legislaciones nacionales y regionales, esto último en aquellas Comunidades Autónomas que tengan legislaciones de Patrimonio Artístico propias.

La Directiva, en su Artículo 5, prevé que la restitución se realice cuando el Estado Miembro requirente interponga "...contra el poseedor $y$, en su caso, contra el tenedor, ante los tribunales competentes del Estado miembro requerido, una acción de restitución del bien cultural que haya salido de forma ilegal de su territorio".

Este procedimiento o acción de restitución no se encuentra desarrollada por nuestra Ley 16/1985, de 25 de Junio, y Reglamentos que la desarrollan, por lo que el procedimiento a aplicar debemos buscarlo en la jurisdicción Civil y, en concreto, con el Interdicto de retener o recobrar la posesión (Arts. 1.651 a 1.662 de la Ley de Enjuiciamiento Civil), proceso que tiene por objeto proteger la posesión contra el despojo ya consumado, con grave perjuicio para el legítimo poseedor: “...procederá cuando el que se halle en la posesión o en la tenencia de una cosa haya sido perturbado en ella por actos que manifiesten la intención de inquietarle o despojarle, o cuando haya sido ya despojado en dicha posesión o tenencia" (Art. I.65। LEC).

El Interdicto es siempre, por naturaleza, un proceso posesorio, de lo cual se deriva como inevitable efecto, que dentro de él únicamente pueden diri- 
mirse cuestiones que tienen relación directa con la posesión, y ello debido a que este procedimiento tiende, una vez reconocido el derecho de posesión, a que pueda el poseedor volver a disfrutar de su derecho, siendo reintegrado en la posesión que ha sido despojado.

Sin embargo, la Directiva 93/7 deja, en parte, sin contenido, ya que se prevén disposiciones obligatorias que no se recogen en el Interdicto de retener o recobrar la posesión y ello debido a dos razones fundamentales:

a) En el Art. 7 de la Directiva Comunitaria se imponen una serie de plazos que afectan a la prescripción de la acción de restitución, así como la irretroactividad de su aplicación, ya que, según lo dispuesto en su Art. 13, “....sólo aplicable a las salidas ilegales del territorio de un Estado miembro que se hayan producido a partir del I de Enero de 1993". b) Se prevé, en su Art. 8, la existencia de indemnizaciones para los poseedores y tenedores de buena fe: "cuando se ordene la restitución, el tribunal competente... concederá al poseedor una indemnización que considere equitativa... siempre que tenga el convencimiento de que el poseedor haya actuado con la diligencia debida en el momento de la adquisición".

Asimismo, en su Art. 12, se dispone que "la propiedad del bien cultural tras su restitución se regirá por la legislación interna del Estado miembro requirente", disposición que viene a coincidir con lo expresado en el Art. 29.I LPHE, que manifiesta que aquellos bienes exportados ilícitamente del país, y a modo de sanción, “...pertenecen al Estado”. No obstante, esta disposición limita exclusivamente esa especie de sanción a los bienes muebles que sean exportados "...sub la autorización requerida por el artículo 5 de esta Ley...”, olvidando la existencia de posibles exportaciones ilegales de Bienes de Interés Cultural en las que no medie ningún tipo de autorización.

Esta atribución al Estado Español de la titularidad de tales bienes, habríamos de entenderla en el sentido de que se trata de la máxima autoridad para la defensa del Patrimonio Histórico, en cuanto que nos encontramos ante un conjunto de bienes portadores de un valor cultural, circunstancia que hace a estos bienes de interés general y pertenecientes a toda la colectividad, en cuanto portadores de “...las expresiones más dignas de aprecio en la aportación histórica de los españoles a la cultura universal..." (Preámbulo LPHE).

Por último, en el Anexo de la Directiva 93/7, se relacionan los bienes que pueden ser restituidos conforme a las disposiciones contenidas en la misma:

I. Objetos arqueológicos de más de 100 años de antigüedad, procedentes de: excavaciones y descubrimientos terrestres y subacuáticos; emplazamientos arqueológicos y colecciones arqueológicas.

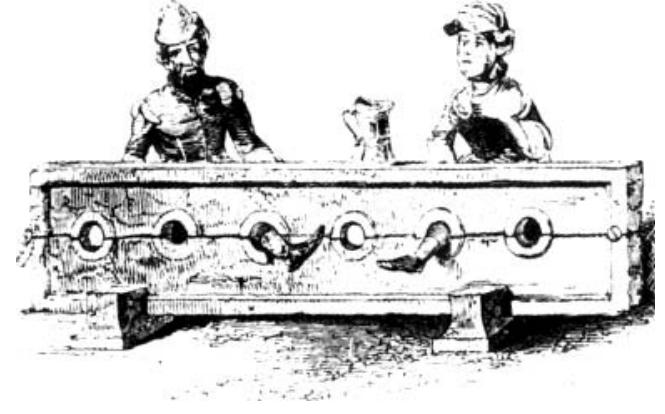

2. Elementos de más de 100 años de antigüedad que formen parte de monumentos artísticos, históricos o religiosos y procedan de la desmembración de los mismos.

3. Cuadros y pinturas hechos totalmente a mano sobre cualquier tipo de soporte y con cualquier material.

4. Mosaicos, distintos de los incluidos en la categoría I ó en la categoría 2, y dibujos hechos totalmente a mano sobre cualquier tipo de soporte y con cualquier material.

5. Grabados, estampas, serigrafías y litografías originales y las matrices respectivas, así como los carteles originales.

6. Obras originales de estatuaria o de escultura y copias obtenidas por el mismo procedimiento que el original, distintas de las incluidas en la categoría I. 7. Fotografías, películas y sus negativos respectivos. 8. Incunables y manuscritos, incluidos en los mapas geográficos y manuscritos incluidos en las partituras musicales, sueltos o en colecciones.

9. Libros de más de 100 años de antigüedad, sueltos o en colecciones.

10. Mapas impresos de más de 200 años de antigüedad.

II. Archivos de todo tipo, cualquiera que sea su soporte, que incluyan elementos de más de 50 años de antigüedad.

12. a) Colecciones y especimenes procedentes de colecciones de zoología, botánica, mineralogía o anatomía.

b) Colecciones que tengan interés histórico, paleontológico, etnográfico o numismático.

13. Medios de transporte de más de 75 años de antigüedad.

14. Otras antigüedades de más de 50 años no comprendidos en las categorías AI a Al 3 .

Con estas líneas, hemos intentado dar a conocer nuestras ideas acerca de la Directiva Comunitaria 93/7, instrumento útil y novedoso, que se convierte en una disposición de obligado cumplimiento para la recuperación de bienes culturales ilegalmente exportados de un Estado de la Unión Europea, sobre todo a partir de la creación del espacio sin fronteras interiores en que se ha convertido Europa, combinándose acertadamente la libre circulación de mercancías con la protección de los "patrimonios históricos y culturales" de cada uno de los miembros firmantes del Tratado de Maastricht.
ALONSO IBÁNEEZ, $M^{a} R$. (1992):

"El Patrimonio Histórico.

Destino Público y Valor

Cultural". Edit. CIVITAS.

Universidad de Oviedo.

Madrid.

ÁLVAREZ ÁLVAREZ, J. L. (1989):

"Estudios sobre el Patrimonio Histórico Español y la Ley de 25 de Junio de 1985”. Edit. CIVITAS. Madrid.

BARRERO RODRÍGUEZ, G. (1990): "La Ordenación Jurídica del Patrimonio Histórico", Edit. CIVITAS Universidad de Sevilla. Madrid.

BENÍTEZ DE LUGO y GUILLÉN F. (1988): "El Patrimonio Cultural Español.Aspectos Jurídicos, Administrativos y Fiscales”. Edit. Comares. Granada.

DEROTU, A. (1992): “ $L a$ Protection des Biens Culturels en Droit Communitaire". Edit. APOGEO. París.

GARCÍA ESCUDERO, P y PENDAS GARCÍA, B. (1986): "El Nuevo Régimen Jurídico del Patrimonio Histórico Español". Colección Cultura y Comunicación $n^{\circ} 25$. Ministerio de Cultura. Madrid.

QUEROL, $M^{a}$ ÁNGELES (1991): "La Incidencia del Futuro Mercado Libre Europeo en el Patrimonio Histórico Español". Boletín del Colegio Profesional de la Educación n. ${ }^{\circ}$ 23. Madrid. Marzo de 1991. 